\title{
Rabaska
}

Revue d'ethnologie de l'Amérique française

\section{REFORD, ALEXANDER et LOUISE TANGUAY. Les Jardins de Métis : le paradis d'Elsie Reford, Montréal, Les Éditions de l’Homme, 2004, 177 p. ISBN2-7619-1220-3}

\section{Jean-Claude Dupont}

Volume 4, 2006

URI : https://id.erudit.org/iderudit/201792ar

DOI : https://doi.org/10.7202/201792ar

Aller au sommaire du numéro

Éditeur(s)

Société québécoise d'ethnologie

ISSN

1703-7433 (imprimé)

1916-7350 (numérique)

Découvrir la revue

Citer ce compte rendu

Dupont, J.-C. (2006). Compte rendu de [REFORD, ALEXANDER et LOUISE

TANGUAY. Les Jardins de Métis : le paradis d'Elsie Reford, Montréal, Les

Éditions de l'Homme, 2004, 177 p. ISBN2-7619-1220-3]. Rabaska, 4, 188-189.

https://doi.org/10.7202/201792ar d'utilisation que vous pouvez consulter en ligne.

https://apropos.erudit.org/fr/usagers/politique-dutilisation/ 
Reford, Alexander et Louise Tanguay. Les Jardins de Métis : le paradis d'Elsie Reford, Montréal, Les Éditions de l'Homme, 2004, 177 p. ISBN27619-1220-3.

Les jardins de Métis, situés sur la rivière Mitis en bordure du fleuve Saint-Laurent, sont une halte obligée. C'est par milliers que les visiteurs arrêtent s'y reposer et s'émerveiller. On les doit à Elsie Reford qui consacra trente ans de sa vie à transformer un petit coin sauvage du Québec en un jardin magnifique. Cette musicienne et horticultrice de talent, en plus de ce petit paradis, laissa une importante collection d'écrits portant surtout sur ses propres expériences et ses connaissances dans le domaine floral. C'est à partir de ces documents et des clichés de Robert Wilson Reford, le mari d'Elsie, de même que des photographies artistiques de Louise Tanguay, que l'arrièrepetit-fils de l'horticultrice, Alexander Reford, a rédigé le volume Les Jardins de Métis : le paradis d'Elsie Reford.

À travers les divers paysages de ce site merveilleux décrits par Alexander Reford, prend forme le portrait intime de la grand-mère et de ses activités. Pendant trois décennies, elle transforma ce qui fut à l'origine l'environnement d'un camp de pêche, creusant la terre, bâtissant des murs de pierre, déplaçant des arbres, échangeant et expérimentant des graines, des plans de fleurs, des arbustes et des arbres, pour finalement créer un jardin qui est seul du genre sous la latitude du $49^{\mathrm{e}}$ parallèle. Et tout cela, parce que, à l'origine, Elsie hérita du camp de pêche au saumon abandonné par son oncle George Stephen, un riche financier londonien opérant des meuneries et des moyens de transport.

L'auteur, Alexander Reford, brosse un tableau de la vie au camp des « gens riches et célèbres » du temps de l'oncle George, dans la seconde moitié du XIX ${ }^{e}$ siècle. L'endroit prenait la forme d'un lieu de rencontre où les invités nouaient des relations sociales et des liens d'affaires. Des berges étaient aménagées pour la baignade, des écuries s'élevaient sur les lieux, des étables renfermaient vaches et autres animaux nécessaires à la consommation quotidienne ; des vastes pâturages, un important bâtiment principal de quelque vingt pièces, des quartiers pour les domestiques, une glacière, un château 
d'eau, etc. Mais, après la mort de son épouse en 1891, le grand-père ne revint plus pêcher et faire des rencontres à son domaine de Métis. Parmi ces gens invités, on reconnaît des Rockefeller et autres hommes de grandes fortunes, des présidents de banque étatsuniens, canadiens et londoniens; des avocats de Wall Street, sans oublier John Sterling, un conseiller juridique dans l'entreprise des chemins de fer, l'un des hommes les plus riches d'Amérique. Puis, en 1918, Estevan Lodge, le camp de Métis, fut offert en cadeau à Elsie Reford.

C'est surtout en 1926 que l'horticultrice conçut son domaine de fleurs de quelque vingt acres et en marqua le départ autour du ruisseau Page qui serpente la propriété. Puis, le temps et les efforts firent leur œuvre ; il en résulta un jardin qui fait l'orgueil de son neveu Alexander et des visiteurs. De cette entreprise, on conserve foule de témoignages, dont des écrits, articles de revues de la Royal Horticultural Society, de la North American Lily Society, etc., traitant des expériences et du succès d'Elsie en climat nordique. Elle décrira ses efforts d'acclimatation d'azalées, de pavots bleus, de fougères, de primevères, de roses de toutes couleurs et de gentianes.

Alexander Reford a su faire surgir dans son ouvrage des jardins authentiques à partir de documents d'archives, de dires de ses parents et grands-parents, de photographies de l'oncle Robert Wilson Reford, sans négliger l'apport artistique des photographies de Louise Tanguay. Le volet de cet ouvrage consacré à la vie sociale au temps du camp de pêche de l'arrièregrand-père est l'un des rares témoignages de pratiques de marketing ou d'établissement de relations commerciales au XIX ${ }^{\mathrm{e}}$ siècle.

Jean-Claude Dupont Québec 